\title{
ITERATIVE METHOD FOR ANALYSIS OF DIMMABLE SELF-OSCILLATING ELECTRONIC BALLAST UNDER BUS VOLTAGE CONTROL
}

\author{
Maikel F. Menke ${ }^{(1)}$, Marcelo F. da Silva ${ }^{(1)}$, Álysson R. Seidel ${ }^{(1)}$, Juliano P. Lopes ${ }^{(2)}$, Marina S. \\ Perdigão $^{(3),(4)}$, José M. Alonso ${ }^{(5)}$ \\ (1) Universidade Federal de Santa Maria, GEDRE, GSEC \\ Santa Maria - RS, Brasil \\ (2) Universidade Tecnológica Federal do Paraná \\ Pato Branco - PR, Brasil \\ (3) Instituto de Telecomunicações, DEEC, Universidade de Coimbra Pólo II \\ Coimbra, Portugal \\ (4) Instituto Politécnico de Coimbra ISEC, DEE \\ Coimbra, Portugal \\ (5) Universidad de Oviedo, Electrical \& Electronics Eng. Dept. \\ Gijón-Asturias, Spain \\ e-mail: seidel@ctism.ufsm.br,perdigao@isec.pt,marcos@uniovi.es
}

\begin{abstract}
This paper presents a predictive method of the self-oscillating electronic ballast (SOEB) behavior under dimming conditions. This work is focused on the bus voltage variation dimming method, where a closed analysis is not possible to carry out without considering the interaction among inverter bus voltage, fluorescent lamp power/resistance nonlinear behavior, and frequency operation of the SOEB. Thus, an iterative method is proposed in order to predict the oscillating frequency related with the fluorescent lamp power under bus voltage variation. Experimental results for a T8 $32 \mathrm{~W}$ fluorescent lamp are obtained in order to compare simulation results, and verify the feasibility of the proposed method.
\end{abstract}

Keywords - Dimming, Electronic Ballast, Fluorescent Lamp, Self-Oscillating.

\section{INTRODUCTION}

The importance of the lighting systems and the use of fluorescent lamps (FL), as well the electronic ballast advantages over the electromagnetic one, are recognized and have been reported in many researches [1]-[3].

Typical electronic ballast consists of two stages: power factor correction (PFC) and half-bridge (HB) series resonant parallel-loaded inverter (LCC) [4]. The PFC stage must be able to meet standards of power factor and current harmonic content [5]. The resonant filter should provide the heating of the filaments, lamp starting, soft-switching and direct current absence in the FL [6]. The inverter gate driver can be implemented by integrated circuits (ICs), but the selfoscillating command circuit (SOCC) is a good alternative, since it presents simplicity, robustness, absence of ICs and their auxiliary sources [1], [7], [8].

Attractive features can be added to the electronic ballast in order to save energy and provide environmental comfort for users. This is possible, for instance by introducing the dimming capability. The classic dimming methods are known as: switching frequency $\left(f_{S}\right)$ variation, duty-cycle $(D)$ variation, changing the resonant filter parameters $\left(Z_{\text {FILTER }}\right)$ and by controlling the bus voltage $\left(V_{B U S}\right)$ [9]. In practice the combination of these methods can be used in order to improve the performance of electronic ballasts. Several solutions have been presented in the literature to implement dimmable electronic ballasts with SOCC, using different dimming methods [3], [4], [10], [11].

In the Dimmable Self-Oscillating Electronic Ballast (DSOEB) where changing the $f_{S}$ is not the selected dimming method, the $f_{S}$ of the SOCC is, by the nature of its operation, load dependent [8], [12]. Thus, it is very difficult to control or predict the exact operating $f_{S}$ of the DSOEB in dimming conditions. Therefore, during the dimming, it is not known the relationship among the DSOEB $f_{S}$, FL power, and the control parameter used ( $D, V_{B U S}$ or $\left.Z_{\text {FILTER }}\right)$ to dim the lamp.

In the DSOEB the $f_{S}$ and the control parameter used ( $D$, $V_{B U S}$ or $\left.Z_{\text {FILTER }}\right)$ to dim the FL are different for each FL power dimming level. Thus, the relationship of these parameters values will be defined according to the DSOEB operating point. If the operating point in the system is predicted it is possible to predict the dimming range, points of FL instability, zero voltage switching (ZVS) [3], electromagnetic interference (EMI), and resonant inductor design.

The DSOEB is usually designed for the nominal lamp power, with $V_{B U S}$ and $f_{S}$ as design parameters [3], [4], [10]. However, the operating point during the whole dimming range is defined empirically. Alternatively, this paper presents an iterative method to predict the DSOEB operating point, where the $V_{B U S}$ is changed to dim the lamp and the correspondent $f_{S}$ and lamp power is calculated. As referred in [13] $V_{B U S}$ dimming technique is better compared to the other methods owing to the higher efficiency obtained during the entire dimming range. The proposed iterative method provides the relationships among $V_{B U S}, f_{S}$, and the FL power, besides evaluating the system stability under dimming conditions.

This paper is organized as follows: In section II the proposed method is presented. Section III shows experimental results and the paper is summarized with the conclusions in Section IV. 


\section{PROPOSED ITERATIVE METHOD}

Figure 1 shows the self-oscillating electronic ballast (SOEB), where the $V_{B U S}$ voltage variation is used for the DSOEB. In this paper, the aim is to predict the operating frequency and FL power of the DSOEB. The PFC is not considered in the analysis because this stage provides the $V_{B U S}$ source. The process related to how the $V_{B U S}$ is changed in the PFC circuit will not be considered here. In addition, the heating current circuit will not be taken into account in the SOCC analysis. First the design of the LCC resonant filter is presented. As next step the SOCC analysis and design will be shown. Then, the proposed iterative method is presented.

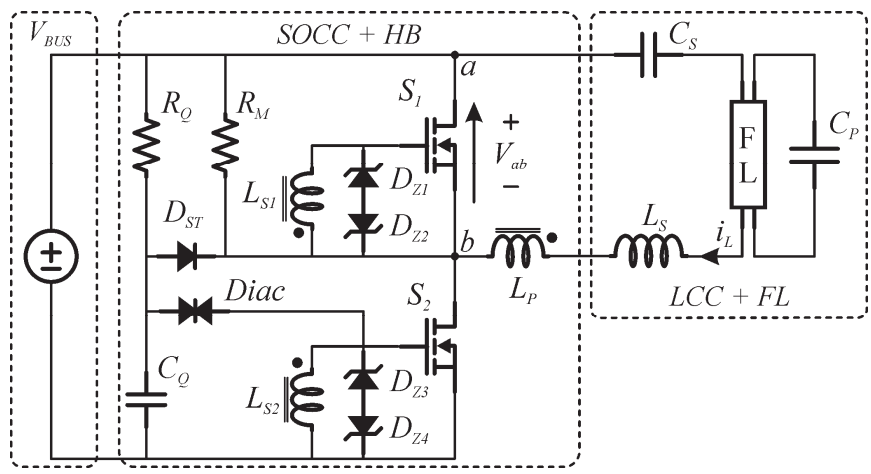

Fig. 1. Self-Oscillating Electronic Ballast (SOEB).

\section{A. Half-bridge Resonant Filter Design}

The design of HB inverter consists in determining the LCC resonant filter components, which provide the heating of the filaments, FL starting, soft-switching and direct current absence in the FL [6], [14], [15].

In this work, the resonant filter is designed using the fundamental of the input filter square-wave-voltage $\left(V_{a b}\right)$ approach and the equivalent resistance model of the FL [14], [15]. The resonant inductor $L_{S}$ and the series resonant capacitor $C_{S}$ are determined according to the methodology presented in [2]. The parallel resonant capacitor $C_{P}$ is designed considering the heating of the filaments of the FL at the rated power [2], [16]. Thus, the LCC filter is designed for the rated FL power. Table I shows the design specifications and respective components.

\section{B. Self-Oscillating Command Circuit Analysis and Design}

1) Representation of $S O E B$ circuit - The behavior of the SOEB shown in Figure 1 is based on the feedback of LCC current $\left(i_{L}\right)$ by means of the current transformer CT, composed of $L_{P}, L_{S 1}$ and $L_{S 2}$. The secondary side of the CT is connected to the gate-source terminals of MOSFETs $S_{1}, S_{2}$ in complementary polarity [3].

Figure 2 shows the equivalent circuit of the SOCC and the respective main waveforms, where, $i_{S}$ is the resonant current and $L_{m}$ is the magnetizing inductance, both reflected to secondary side of the CT. The zener current $i_{Z}$ is the subtraction of the magnetizing current $i_{m}$ and $i_{S}$. When $i_{S}$ is equal to $i_{m}$, the $i_{Z}$ current crosses zero according to the time instants $t_{1}, t_{2}$, and $t_{3}$ (Figure 2). As a result, the gate-source voltage $\left(V_{Z}\right)$ of switches $S_{I}$ and $S_{2}$ change the state between on or off according to the polarity of $i_{z}$.

Figure 1 can be represented in terms of a block diagram as shown in Figure 3.a [8], where the HB inverter and the dc source $\left(V_{B U S}\right)$ are represented by a hard-limit nonlinearity.

TABLE I

Resonant Filter Parameters

\begin{tabular}{ll}
\hline \multicolumn{3}{c}{ Design Specification } \\
\hline Bus voltage & $300 \mathrm{~V}$ \\
\hline Switching frequency & $35 \mathrm{kHz}$ \\
\hline Fluorescent lamp & OSRAM T8 32W \\
\hline FL resistance & $540 \Omega$ \\
\hline FL Nominal voltage & $130 \mathrm{~V}_{\mathrm{RMS}}$ \\
\hline \multicolumn{3}{c}{$\quad$ Resonant Filter } \\
\hline $\mathrm{L}_{\mathrm{S}} \quad$ Series resonant inductor & $2.64 \mathrm{mH}$ \\
\hline $\mathrm{C}_{\mathrm{S}} \quad$ Series resonant capacitor & $170 \mathrm{nF}$ \\
\hline $\mathrm{C}_{\mathrm{P}} \quad$ Parallel resonant capacitor & $8.2 \mathrm{nF}$ \\
\hline
\end{tabular}
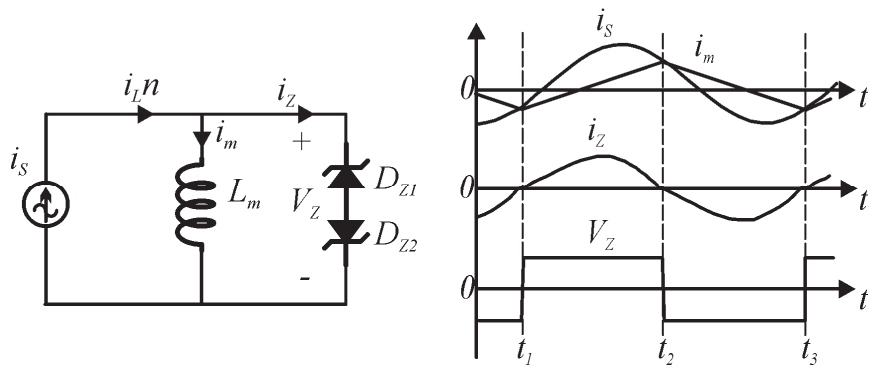

Fig. 2. Equivalent circuit, and mains waveforms of the SOOC.

In addition, $G_{F}(s)$ is the transfer function from voltage $V_{a b}$ to the resonant current $i_{L}$, given by (1), and $G_{M}(s)$ is the transfer function from the gate-source voltage $\left(V_{Z}\right)$ to the magnetizing current $i_{m}$, defined by (2) [8]:

$$
\begin{gathered}
G_{F}(s)=\frac{s^{2}+a s}{s^{3}+a s^{2}+b s+c} \\
G_{M}(s)=\frac{1}{L_{m} s}
\end{gathered}
$$

where:

$$
a=\frac{1}{R_{F L} C_{P}} ; b=\frac{1}{L_{S} C_{S}}+\frac{1}{L_{S} C_{P}} ; c=\frac{1}{R_{F L} L_{S} C_{S} C_{P}}
$$

In order to determine the behavior of the circuit in Figure 1, the describing function (DF) method and the extended Nyquist criterion (ENC) are used [8], [17]. Thus, to use the DF and ENC, Figure 3. a can be represented in terms of reduced block diagrams as shown in Figure 3.b. The DF that is associated with the hard limit nonlinearity is given by (3), and the linear elements transfer function is defined in (4):

$$
\begin{gathered}
N\left(I_{Z}\right)=\frac{4 V_{Z}}{\pi I_{Z}} \\
G(s)=G_{M}(s)-K G_{F}(s) n
\end{gathered}
$$


where $K=V_{B U S} /\left(2 V_{Z}\right)$ is the gain to obtain $V_{a b}$ from $V_{Z}$, $n=n_{P} / n_{S}, n_{P}$ and $n_{S}$ are the number of turns of the CT primary and secondary windings, respectively.

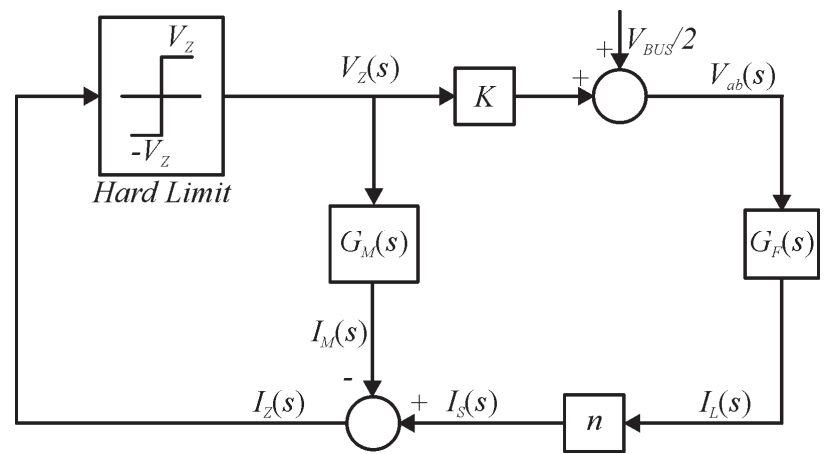

(a)

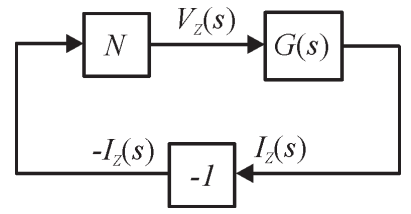

(b)

Fig. 3. SOEB block diagram (a) and reduced block diagram (b).

Analyzing Figure 3.b, being $s=j \oplus$, if the self-sustained oscillation exists, the amplitude of $i_{Z}$, and the value of $f_{S}$ or angular frequency $\omega=2 . \pi . f_{\mathrm{S}}$ can be determined from the system characteristic equation, given by (5) [8]. Rearranging (5) it becomes (6).

$$
\begin{gathered}
1+N\left(I_{Z}\right) G(s)=0 \\
G(s)=-\frac{1}{N\left(I_{Z}\right)}
\end{gathered}
$$

The frequency response of $G(j \oplus)=G(s)$ and the negative inverse describing function $-1 / N\left(I_{Z}\right)$ can be plotted in the complex plane as shown in Figure 4. If both curves intersect, then there is a limit cycle and the values of $I_{Z}$ and $₫$ correspond to the intersection point and the solution of (6) [8], [17]. However, the system just present self-sustained oscillation when the $G(j . \oplus)$ crosses $-1 / N\left(I_{Z}\right)$ in clockwise direction.

Observing the plot of Figure 4 the negative inverse describing function presents only the real part and it intercepts $G(j \omega)$ at a determined frequency $\Phi_{\mathrm{s}}$. Thus, (7) can be applied. Substituting (4) in (7), (8) is obtained. Then, the magnetizing inductance $L_{m}$ can be solved using (8) [8]. Therefore, it is possible to develop a design procedure for the SOCC that determines a possible value of $f_{S}$ for stable operation.

$$
\begin{gathered}
\operatorname{Im}(G(j \omega))=0 \\
\frac{-1}{\omega L_{m}}-\frac{K n}{L_{S}} \frac{\omega a\left(c-\omega^{2} a\right)+\omega^{2}\left(\omega b-\omega^{3}\right)}{\left(c-\omega^{2} a\right)^{2}+\left(\omega b-\omega^{3}\right)^{2}}=0
\end{gathered}
$$

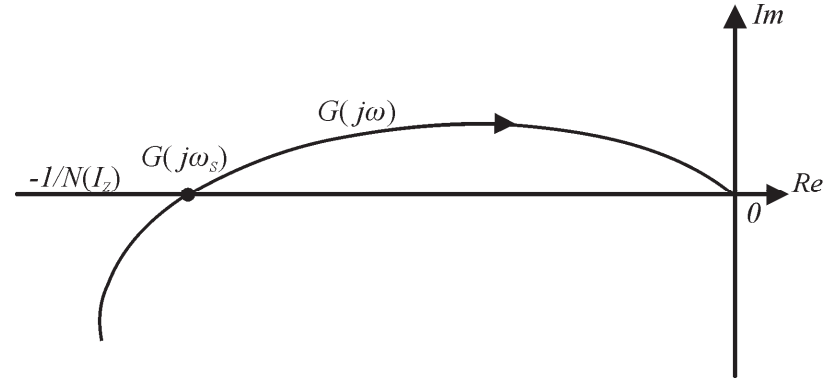

Fig. 4. Nyquist plot of SOEB.

2) SOCC design - The SOCC design consists in determining the magnetizing inductance $L_{m}$ from the main design specifications: value of zener voltage and current to protect the MOSFETs and to define a limit of magnetizing current, the FL power, $f_{S}$, and $V_{B U S}$. In this work the SOCC is designed following the methodology presented in [8], and using the same design specifications shown in Table I. The self-oscillating command circuit components are presented in Table II.

TABLE II

Self-Oscillating Command Circuit Components

\begin{tabular}{lll}
\hline \multicolumn{3}{c}{ Self-Oscillating Command Circuit } \\
\hline $\mathrm{L}_{\mathrm{P}}, \mathrm{L}_{\mathrm{S} 1}, \mathrm{~L}_{\mathrm{S} 2}$ & Current Transformer Inductance & $49 / 411 / 411 \mu \mathrm{H}$ \\
\hline $\mathrm{N}_{\mathrm{P}}, \mathrm{N}_{\mathrm{S} 1}, \mathrm{~N}_{\mathrm{S} 2}$ & Windings Number of Turns & $4 / 12 / 12$ \\
\hline $\mathrm{D}_{\mathrm{Z1} 1}-\mathrm{D}_{\mathrm{Z} 4}$ & Zener Diode & $12 \mathrm{~V} ; 1 / 2 \mathrm{~W}$ \\
\hline $\mathrm{S}_{1}, \mathrm{~S}_{2}$ & MOSFET & IRF740 \\
\hline \multicolumn{3}{c}{$\quad$ Start Circuit } \\
\hline $\mathrm{R}_{\mathrm{Q}} / \mathrm{R}_{\mathrm{M}}$ & Resistor & $270 \mathrm{k} \Omega / 470 \mathrm{k} \Omega$ \\
\hline $\mathrm{C}_{\mathrm{Q}}$ & Capacitor & $100 \mathrm{nF}$ \\
\hline Diac & Diac & $\mathrm{DB} 3$ \\
\hline
\end{tabular}

In order to evaluate the dimming range, FL stable operation, ZVS, and the size of resonant inductor the operating point should be previously determined. Thus, in the next section an iterative method to predict the DSOEB operating point is proposed.

\section{Proposed Iterative Method}

Figure 5 summarizes the proposal of this paper through a flowchart. Each step of this method is explained as follows:

1) Initialization - Firstly, it starts by defining the LCC filter, the SOCC components, and the design parameters previously known.

2) Define $P_{i}-$ In the next step $P_{i}$ is defined as the desired FL power, which is used to calculate the respective $V_{B U S_{-} i}$ necessary to supply the $\mathrm{HB}$ inverter, for the resulting $f_{S O_{-} i}$ of the DSOEB.

3) $R_{F L}\left(P_{i}\right)$ - In this step the FL resistance is calculated by (9), which represents the FL resistance as a function of its own power according the FL model shown in 0 .

$$
R_{F L}\left(P_{i}\right)=2274 e^{-0.046 P_{i}}+8945 e^{-0.204 P_{i}}
$$

4) Calculate $f_{S O_{-} i}-$ At this point, $P_{i}, R_{F L}\left(P_{i}\right)$ and the supposed respective $V_{B U S_{\_} k}$ are known, and the self-oscillation frequency $\left(f_{S_{-} i}\right)$ can be determined by solving (6). Initially $V_{B U S}$ is supposed to be $V_{B U S_{-} k=0}=V_{B U S}$, being $k$ an intermediary index in the loop to obtain $f_{S O_{-} i}$ when $P_{S O_{-} k} \approx P_{i}$. 


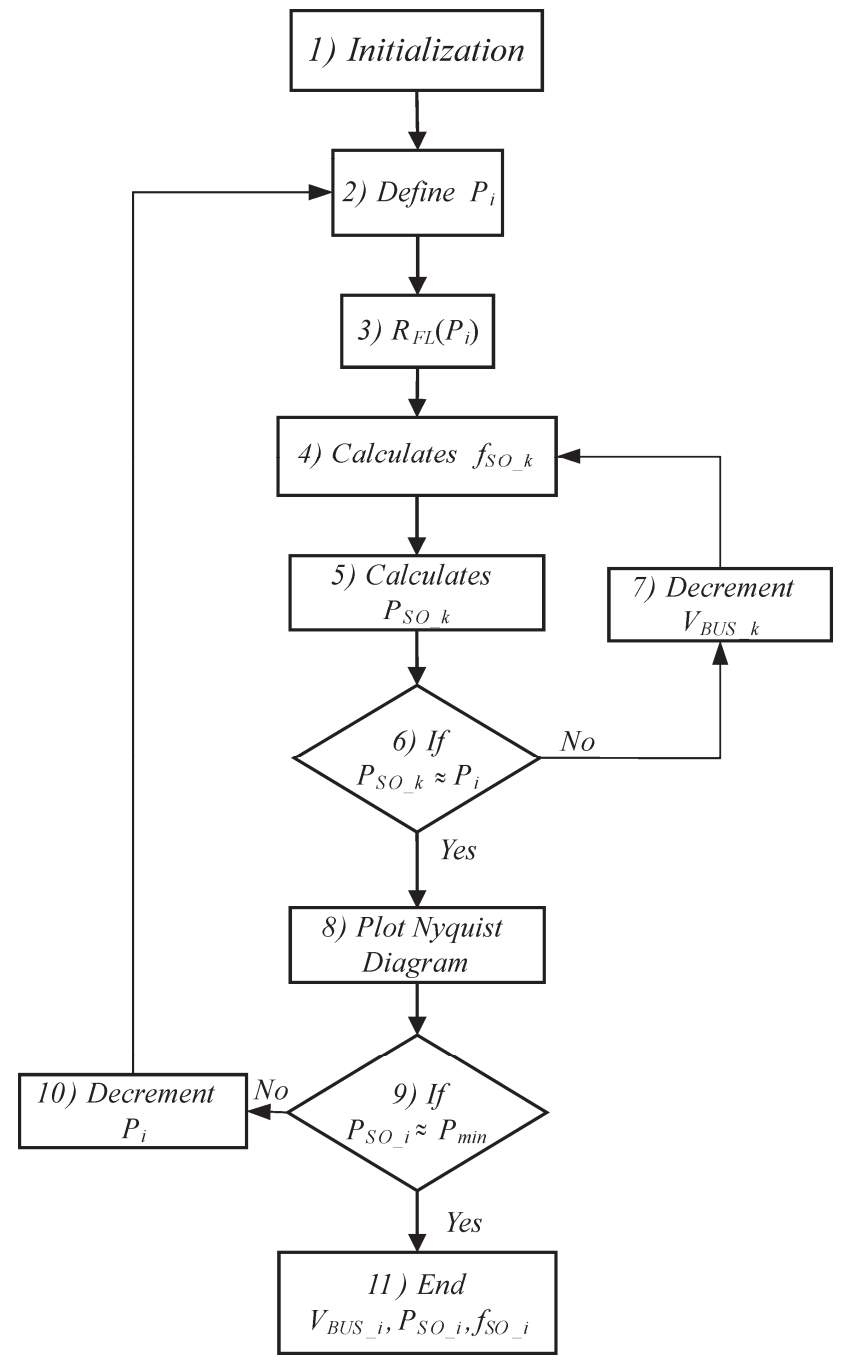

Fig. 5. Flowchart of the proposed iterative method to predict the DSOEB operating point under $V_{B U S}$ dimming technique: flowchart.

5) Calculates $P_{S O \_k}-$ With the calculated $f_{S O \_k}$, and knowing the filter parameters, the lamp power with the operating $f_{S O} k$ is calculated. The FL power $P_{S O \_}$is calculated by [6]:

$$
P_{F L}=\frac{\left(\frac{V_{B U S} \sqrt{2}}{\pi}\right)^{2} R_{F L}\left(1+C_{p}^{2} R_{F L}^{2} \omega^{2}\right)}{R_{F L}^{2}+\omega^{2}\left(\left(L_{S}-\frac{1}{C_{S} \omega^{2}}\right)\left(1+C_{p}^{2} R_{F L}^{2} \omega^{2}\right)-R_{F L}^{2} C_{P}\right)^{2}} .
$$

6) First decision - If the calculated power $P_{S O \_}$is close to the desired FL power $P_{i}$, then the respective $V_{B U S_{-} i}$ and $f_{S O} i$ are known. The error adopted is $1 \%$.

7) Decrement $V_{B U S_{-} k}-V_{B U S_{-} k}$ is decremented and the program return to step 4 , with a new supposed $V_{B U S_{-} k+1}$.

8) Plot Nyquist Diagram - The Nyquist diagram is plotted, and with the extended Nyquist criterion it is possible to evaluate if the system presents a self-sustained oscillation.

9) Second decision - At step 9, if the $P_{\mathrm{SO}_{-} i}$ is close to the minimum FL power, using $1 \%$ error, then execution goes to step 11 and the process is finished. The minimum FL power depends on the desired dimming range which the operating points will be known.
10) Decrement $P_{i}$ - If $P_{S O_{-} i}$ is greater than the minimum FL power, $P_{i}$ is decremented. The same process is repeated until the $P_{i}$ is close to the minimum FL power adopted.

11) End - The flowchart produces three vectors that are related to the FL power, $V_{B U S}$ and the $f_{S}$ of the DSOEB.

It is important to mention that the FL equivalent resistance is not constant when the FL power is changed. Therefore, adding the FL model in this method provides better results than when this characteristic of the FL is not considered.

\section{EXPERIMENTAL RESULTS}

In this section the proposed iterative method is implemented and tested. The implementation can be carried out using any software that allows iterative calculus, as MATLAB. Tables I and II summarize the design parameters and used components. In order to show the feasibility and to evaluate the proposed method, experimental results were obtained with three different filters, where the first analysis is carried out with the designed filter. The other two filters are similar to the designed one, where only capacitor $C_{P}$ is changed, $L_{S}$ and $C_{S}$ were maintained constant, in order to evaluate this method comparing with experimental results. For instance, $C_{P}$ values of $6.8 \mathrm{nF}$ and $10 \mathrm{nF}$ were tested. Then, the operating point for this three filters are compared, between experimental and proposed iterative method results.

Figure 6 shows the DSOEB operating point under dimming by changing the $V_{B U S}$. This figure shows the experimental results and calculated values obtained from the proposed method. It is possible to verify a good approximation between the results for three different filters values considering the $C_{P}$ variation: 1) $C_{P}=8.2 \mathrm{nF}$ for the designed filter, 2) $C_{P}=6.8$ $\mathrm{nF}$, and 3) $C_{P}=10 \mathrm{nF}$.

Usually, the first analysis performed in the DSOEB is to consider the $f_{S}$ constant. Figure 7.a shows the results of FL power for this situation. It can be seen worst results comparing the proposed iterative method. Figure 7.b shows the relative error of the FL power and $f_{S}$ for the predicted values using the iterative method, taking as reference the experimental results. Besides, it is shown also the FL power error considering a fixed $f_{S}$ approximation. As it can be seen, the maximum error of the FL power and $f_{S}$ for the proposed method results are $4.5 \%$ and $3 \%$, respectively. Once for the fixed $f_{S}$ approximation the FL power relative error is greater than $25 \%$.

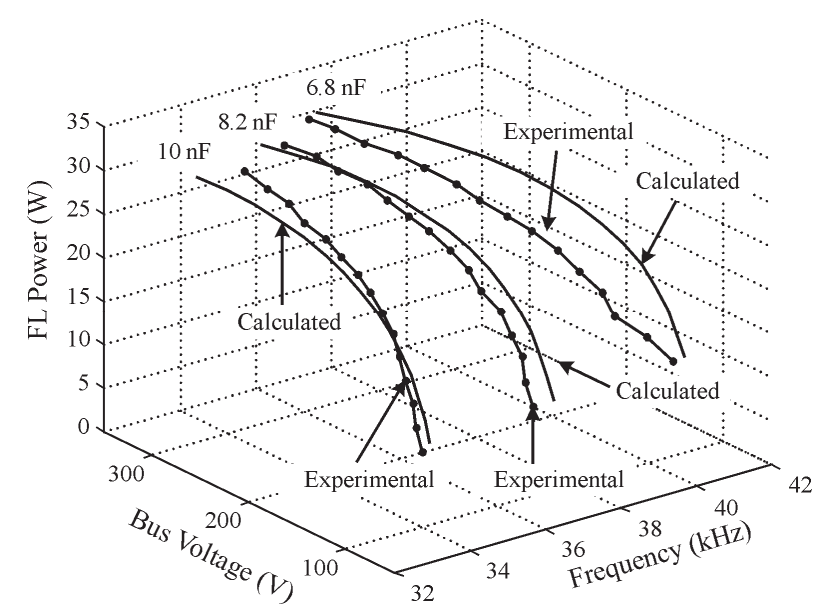

Fig. 6. DSOEB operating point under $V_{B U S}$ technique dimming. 
Figures 8.a and 8.b show the result for $C_{P}=10 \mathrm{nF}$. Figure 8.a shows the comparison between the proposed method and fixed $f_{S}$ approximation results. The maximum $f_{S}$ error is lower than $4.5 \%$ for the whole dimming range, and the maximum FL power error is lower than $4.5 \%$ for dimming until $13 \mathrm{~W}$ for the proposed method. Once for dimming level lower than $13 \mathrm{~W}$ the maximum error is lower than $8.5 \%$, being acceptable compared to the error for the fixed $f_{S}$ approximation that is greater than 30\%. In Figure 9 the results for $C_{P}=6.8 \mathrm{nF}$ are shown. Analyzing the proposed method results the maximum

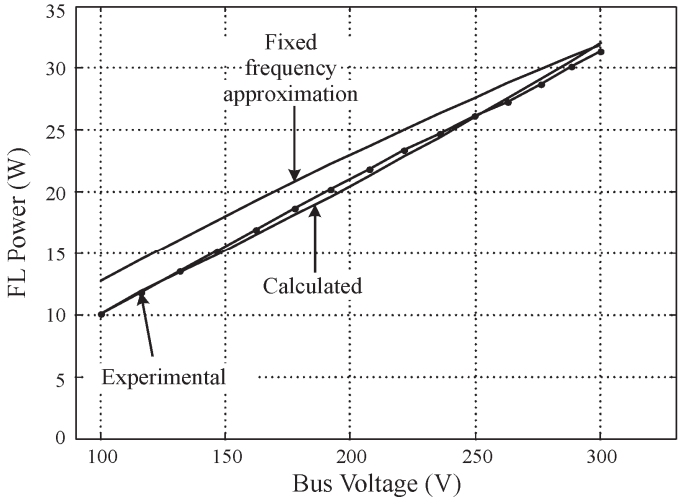

(a) error for FL power and $f_{S}$ are $7.5 \%$ and $5.5 \%$, respectively, while for the fixed $f_{S}$ approximation the maximum error is greater than $15 \%$.

Figure 10 shows the experimental waveforms for the designed filter $\left(\mathrm{C}_{\mathrm{P}}=8.2 \mathrm{nF}\right)$. Figures 10.a, 10.b and 10.c show the FL power, voltage and discharge current. As can be seen, a wide dimming range is obtained, between $31.6 \mathrm{~W}$ and $10 \mathrm{~W}$, similar to the predicted one, which was between $32.05 \mathrm{~W}$ and $10.10 \mathrm{~W}$.

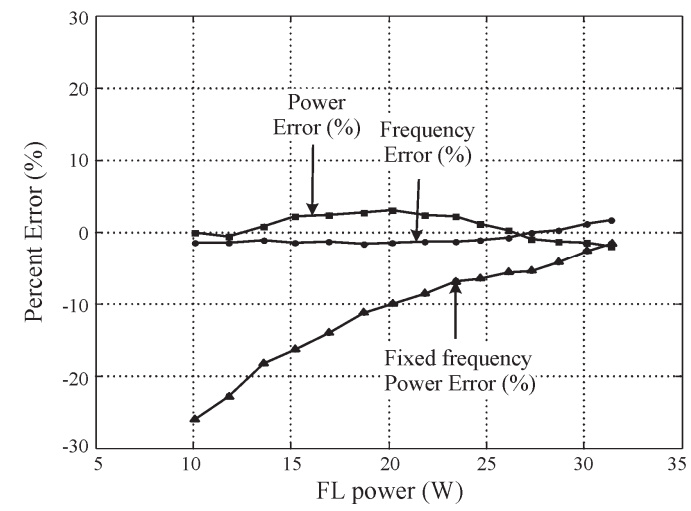

(b)

Fig. 7. Comparison among experimental results, fixed frequency approximation, and proposed iterative method result for the designed resonant filter: (a) FL Power versus $V_{B U S}$ for the designed resonant filter. (b) Percent error.

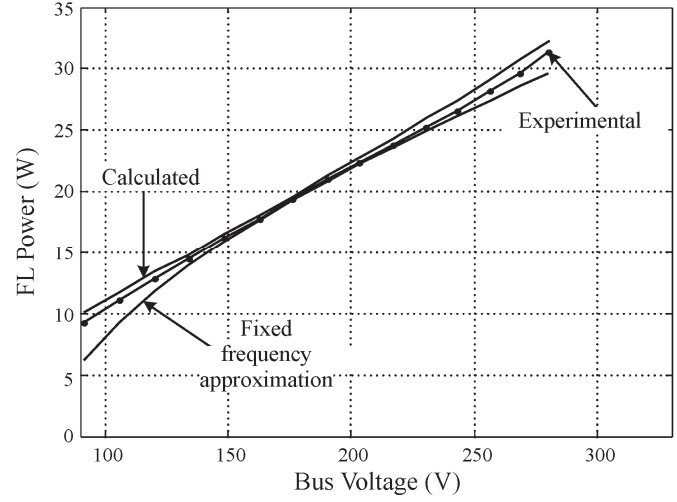

(a)

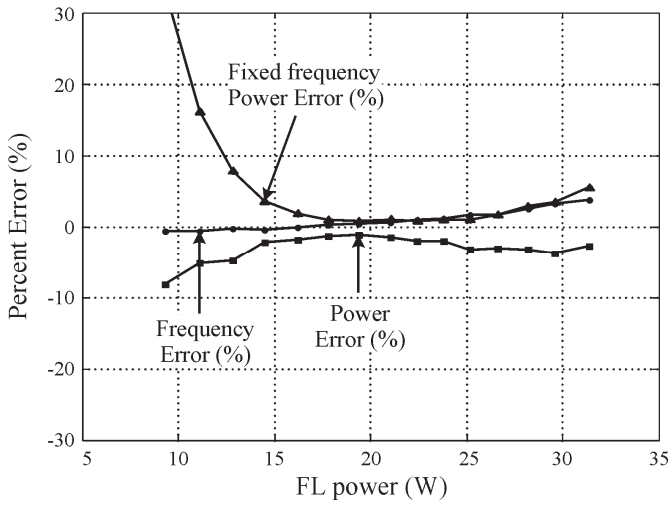

(b)

Fig. 8. Comparison among experimental results, fixed frequency approximation, and proposed iterative method result for the designed resonant filter with $C_{P}=10 n F$ : (a) FL Power versus $V_{B U S}$ for the designed resonant filter; (b) Percent error.

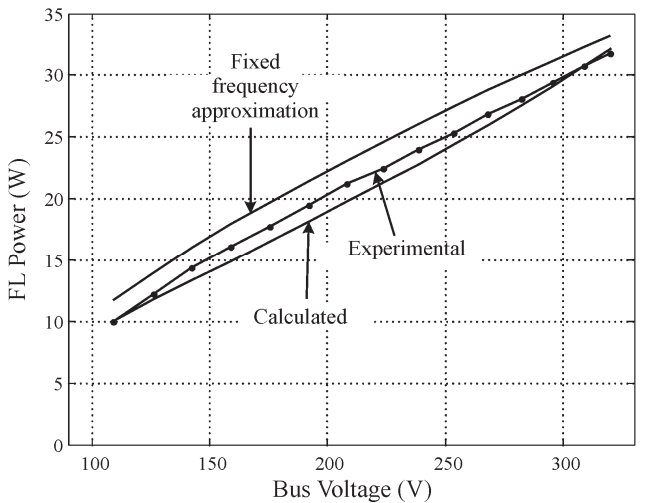

(a)

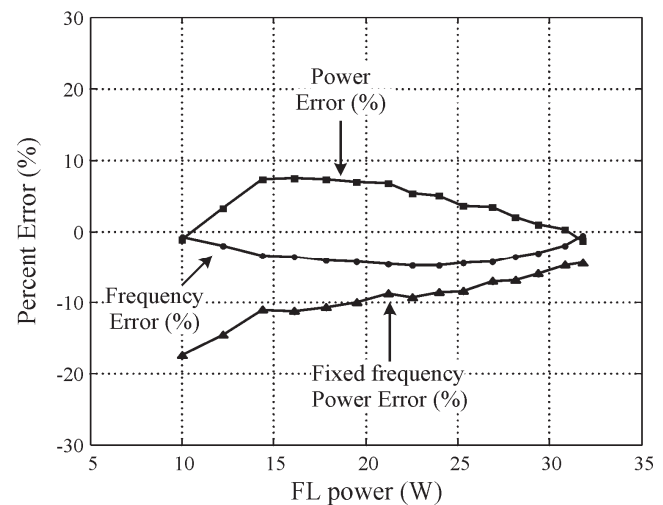

(b)

Fig. 9. Comparison among experimental results, fixed frequency approximation, and proposed iterative method result for the designed resonant filter with $C_{P}=6.8 n F$ : (a) FL Power versus $V_{B U S}$ for the designed resonant filter; (b) Percent error. 
On the other hand, the predicted frequency for the maximum and minimum FL power are $34.88 \mathrm{kHz}$ and 37.53 $\mathrm{kHz}$, respectively, also close to the experimental one, $36.06 \mathrm{kHz}$ and $36.39 \mathrm{kHz}$. In addition, Figure 10.d, 10.e and

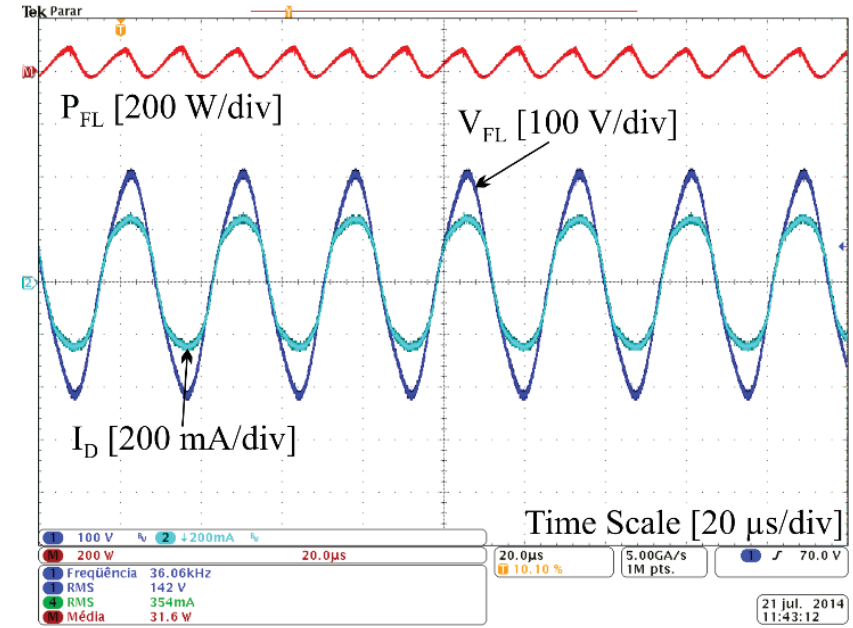

(a)

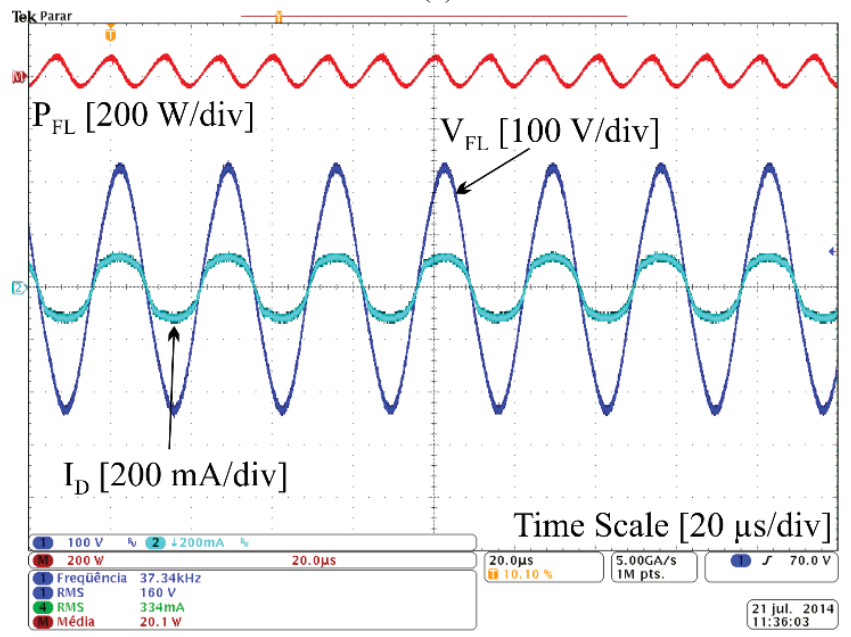

(b)

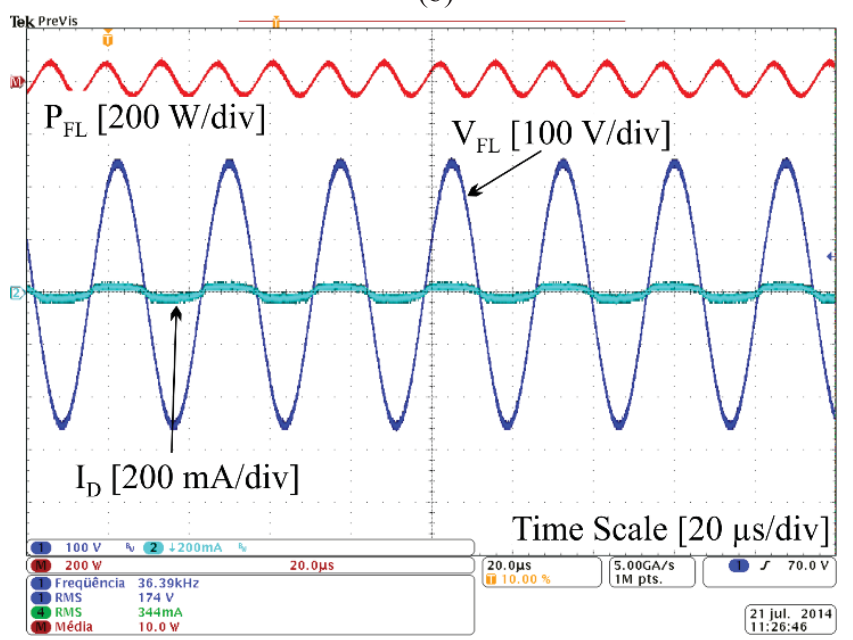

(c) 10.f show the MOSFET $S_{2}$ voltage and current, where it can be seen that the ZVS is achieved for both maximum, medium and minimum power. Once, when $S_{2}$ turn on, the resonant current circulates through the body diode, negative current.

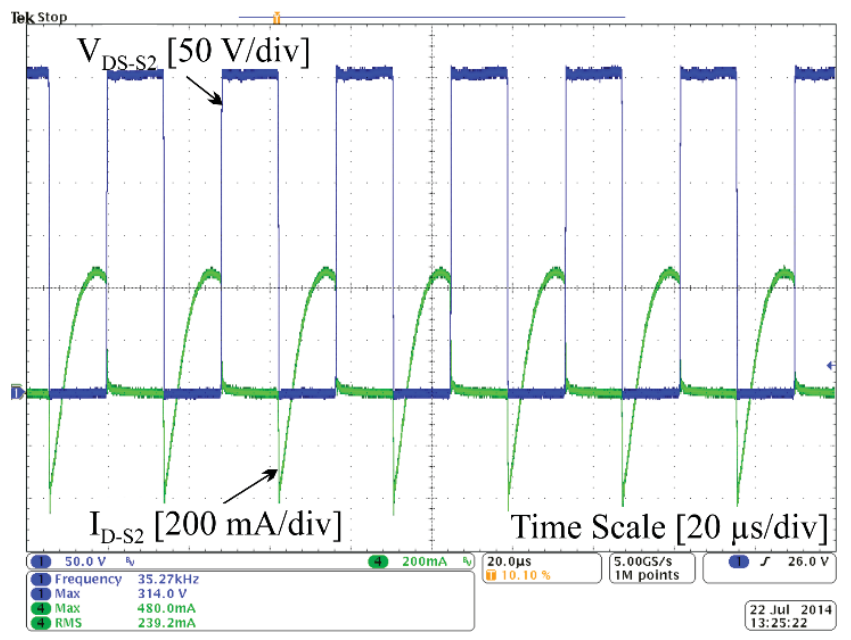

(d)

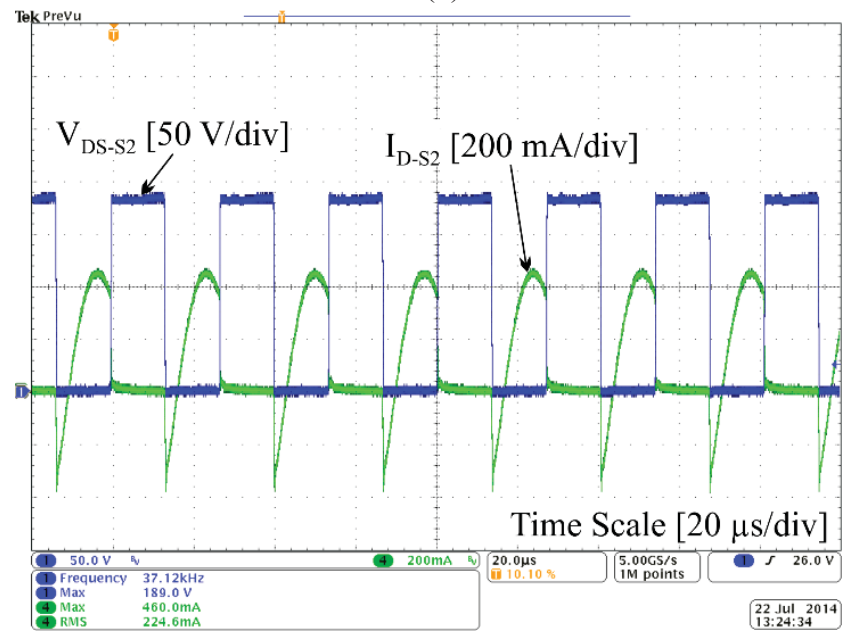

(e)

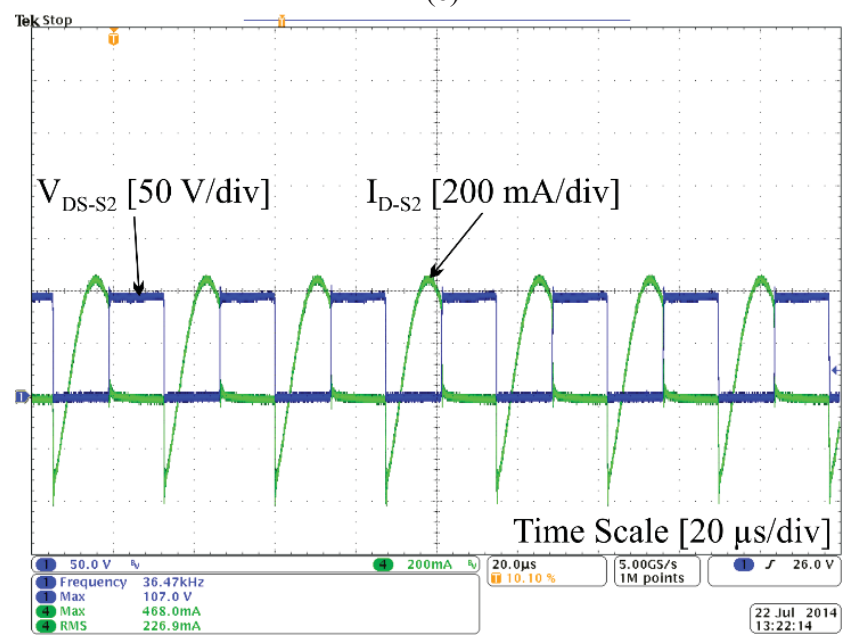

(f)

Fig. 10. Experimental waveforms for $C_{P}=8.2 \mathrm{nF}$ : (a) FL voltage $\left(V_{F L}\right)$, discharge current $\left(\mathrm{I}_{D}\right)$, and power $\left(\mathrm{P}_{F L}\right)$, for the maximum FL power $(31.6 \mathrm{~W})$; (b) FL voltage, discharge current, and power, for medium FL power (20.1 W); (c) FL voltage, discharge current, and power, for minimum FL power $(10 \mathrm{~W})$; (d) $S_{2}$ Drain-source voltage $\left(V_{D S-S 2}\right)$, and current (I $\left.\mathrm{I}_{D-S 2}\right)$ for the maximum FL power $(31.6 \mathrm{~W})$; (e) $S_{2}$ Drain-source voltage, and current for the medium FL power $(20.1 \mathrm{~W})$; (f) $S_{2}$ Drain-source voltage, and current for the minimum FL power (10 W). 
Another interesting feature of the implemented method is the possibility to evaluate the system stability under dimming conditions. Figure 11, 12 and 13 show the Nyquist diagram of the DSOEB for each FL power operating point. Then, using the extended Nyquist stability criterion it is possible to verify if the system presents self-sustained oscillation, since the $G(j \oplus)$ crosses $-1 / N\left(I_{Z}\right)$ in clockwise direction.

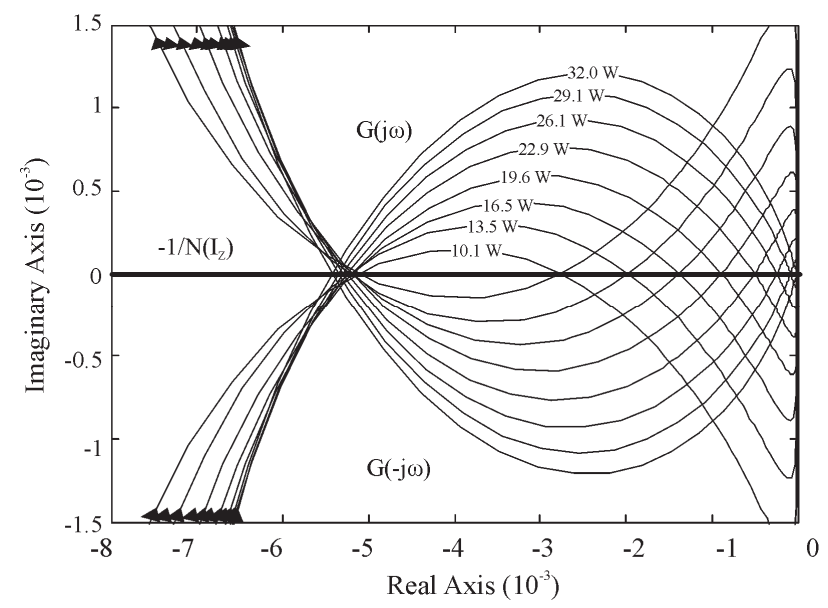

Fig. 11. Nyquist Diagram of the DSOEB for the designed resonant filter.

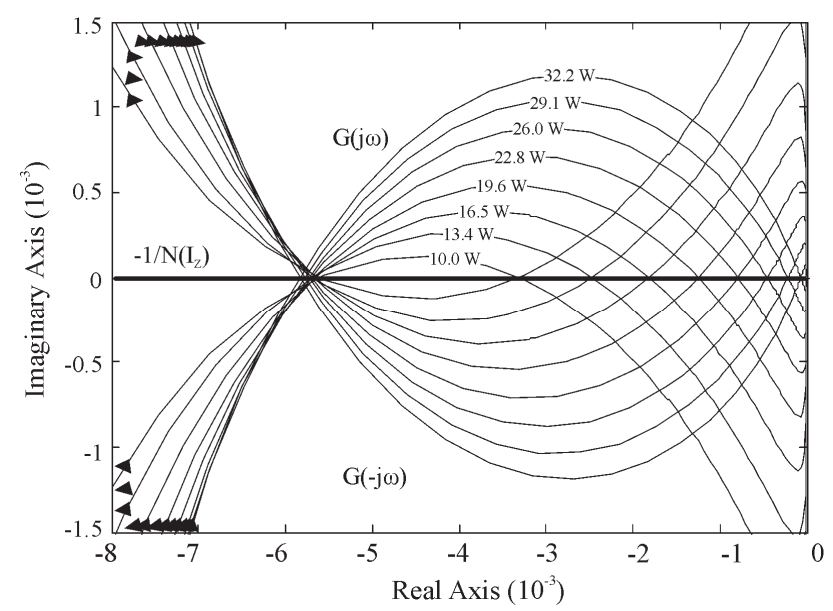

Fig. 12. Nyquist Diagram of the DSOEB for the designed resonant filter, with $C_{P}=10 \mathrm{nF}$.

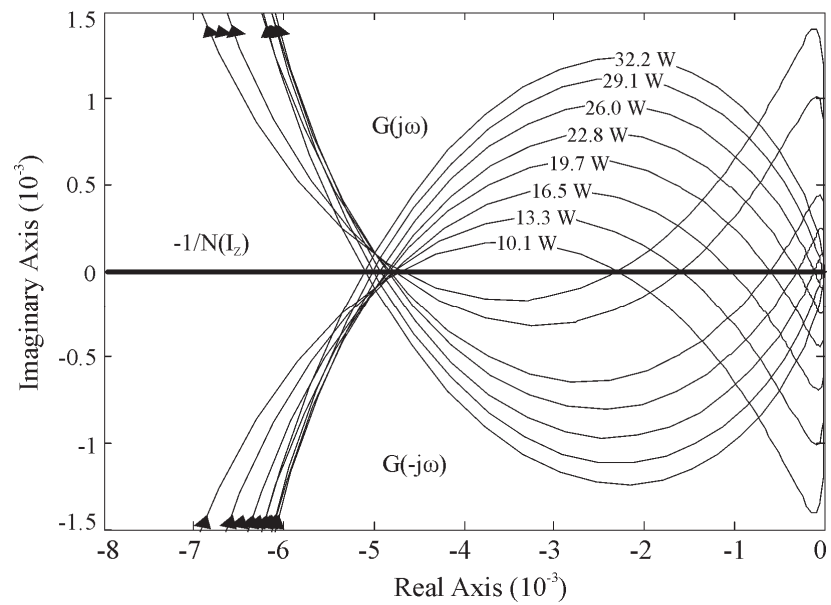

Fig. 13. Nyquist Diagram of the DSOEB for the designed resonant filter, with $C_{P}=6.8 \mathrm{nF}$.

\section{CONCLUSION}

In this work an iterative method was implemented to predict the switching frequency, fluorescent lamp power, and the bus voltage in the self-oscillating dimmable electronic ballast, with bus voltage dimming technique.

Experimental results confirm the feasibility of the proposed method, with a negligible relative percent error for the FL power and switching frequency by comparing experimental and calculated values by the proposed iterative method. Besides, it is possible to evaluate the system stability under dimming conditions.

\section{ACKNOWLEDGEMENT}

This work was co-sponsored by the Brazilian government (CAPES/DGU and CEEE-D) and by the Spanish government (DGPU PHB2010-0145-PC).

\section{REFERENCES}

[1] S. S. M. Chan, H.S.H. Chung, R.S.Y. Hui, "Design and Analysis of an IC-less Self-oscillating Series Resonant Inverter for Dimmable Electronic Ballasts", IEEE Transactions on Power Electronics, vol. 20, no 6, pp. 1450-1458, November 2005.

[2] J. de P. Lopes, M. F. Menke, F. E. Bisogno, R. N. do Prado, J. Ribas, and J. M. Alonso, "Automatic Lamp Detection Technique for Fluorescent Lamp Electronic Ballast", in Proc. of IEEE IAS Annual Meeting, pp. 1-8, 2012.

[3] A. R. Seidel, F. E. Bisogno, H. Pinheiro, and R. N. do Prado, "Self-Oscillating Dimmable Electronic Ballast", IEEE Transactions on Industrial Electronics, vol. 50, no. 6, pp. 1267-1274, December 2003.

[4] S. S. M. Chan, H. S. H. Chung, R. S. Y. Hui, "Selfoscillating Dimmable Electronic Ballast for Fluorescent Lamps", IEEE Power Electronics Letters, vol. 2, no. 3, pp. 87-91, September 2004.

[5] IEC 61000-3-2, Limits for Harmonic Current Emissions Part 3-4: limits, International Standards, International Electrotechnical Commission, $3^{\text {a }}$ Ed., 2005.

[6] F. E. Bisogno, A. R. Seidel, R. Holsbach, and R. N. do Prado, "Resonant Filter Applications in Electronic Ballast", in Proc. of IEEE IAS Annual Meeting, vol. 1, pp. 348-354, 2002.

[7] A. R. Seidel, F. E. Bisogno, R. K. Pavão, R. N. do Prado, "Projeto Do Reator Eletrônico Auto-oscilante", Revista Eletrônica de Potência, SOBRAEP, vol 9, nº 1, pp. 53-61, June 2004.

[8] A. R. Seidel, F. E. Bisogno, R. N. do Prado, "A Design Methodology for a Self-Oscillating Electronic Ballast", IEEE Transaction on Industry Applications, vol. 43, no. 6, pp. 1524-1533, November/December 2007.

[9] M. F da Silva, J. Fraytag, R. Marchesan, V. L. Rosa, M. A. Dalla Costa, J. M. Alonso, R. N. do Prado, "A dimmable Cuk Half-Bridge Single-Stage Converter Applied to Electrodeless Fluorescent Lamps", Proc. In EPE-PEMC, pp. ds1b.6-1 - ds1b.6-5, 2012.

[10] J.-C. Hsieh, J.-L. Lin, "Novel Single-Stage SelfOscillating Dimmable Electronic Ballast With High 
Power Factor Correction", IEEE Transactions on Industrial Electronics, vol. 58, no. 1, pp. 250-262, January 2011.

[11] S. Borekci, S. Once, "Dimming Self-Oscillating ballast by Variable Inductor”, Electronic Letters, vol. 43, no. 14, July 2007.

[12] F. Tao, Q. Zhao, F. C. Lee, N. Onishi, "Self-Oscillating Electronic Ballast with Dimming Control", Proc. In IEEE PESC, vol. 4, pp. 1818-1823, 2001

[13] Y. K. E. Ho, S. T. S. Lee, H. S.-H. Chung, S. Y. Hui, “A Comparative Study on Dimming Control Methods for Electronic Ballasts", IEEE Transactions on Power Electronics, vol. 16, no. 6, pp. 828-836, November 2001.

[14] F. T. Wakabayashi, C. A. Canesin, “An Improved Design Procedure for LCC Resonant Filter of Dimmable Electronic Ballasts for Fluorescent Lamps Based on Lamp Model", IEEE Transactions on Power Electronics, vol. 20, no 5, pp. 1186-1196, September 2005.

\section{BIOGRAPHIES}

Maikel Fernando Menke was born in Três de Maio, Brazil, in 1989. He is currently doing his graduation course in electrical engineering in the Federal University of Santa Maria. He is a researcher in the Electronic Ballast Research Group (GEDRE Intelligence on lighting) and Electrical and Computational Systems Research and Development Group (GSEC), since 2009. His main research interests include $\mathrm{dc} / \mathrm{dc}$ converters, power factor correction stages, dimming systems, resonant filters, high-frequency electronic ballasts, fluorescent lamps, and self-oscillating command circuits.

Marcelo Freitas da Silva was born in São Paulo, Brazil, in 1970. $\mathrm{He}$ received the B.S., M.Sc. and Ph.D. degree in electrical engineering from the Federal University of Santa Maria, Santa Maria, Brazil, in 1995, 2000 and 2012, respectively. In 2013, he was with the University of Oviedo, Spain, as a Postdoctoral Research Scholar. Since 1993, he has been with the Federal University of Santa Maria, where he is currently a Professor in the Colégio Técnico Industrial de Santa Maria (CTISM). He also serves as a Reviewer for IEEE journal and conferences in the field of power electronics. He has been with the Electronic Ballast Research Group (GEDRE), Federal University of Santa Maria, as a Researcher. Electrical and Computational Systems Research and Development Group (GSEC) since 2010. His research interests include electronic ballasts, lamps, dimming systems, power factor correction, fluorescent lamps and LEDs.

Juliano de Pelegrini Lopes was born in Cruz Alta, Brazil, in 1983. He received the B.S. and M.Sc. degrees in electrical engineering from the Federal University of Santa Maria, Santa Maria, Brazil, in 2008 and 2010, respectively, where he is currently working toward the Ph.D. degree in electrical engineering. Since 2013, he has been a Professor with Universidade Tecnológica Federal do Paraná, Pato Branco, Brazil. His research interests include electronic ballasts, $\mathrm{dc}-\mathrm{dc}$ converters, power factor correction, dimming systems, resonant converters, and fluorescent lamps.

Álysson Raniere Seidel was born in São Pedro do Sul, Brazil, in 1975. He received the B.S. and Ph.D. degrees in electrical engineering from the Federal University of Santa Maria, Santa Maria, Brazil, in 1999 and 2004, respectively. From 2004 to 2008, he was an Associate Professor in the Department of Electrical Engineering, University of Passo Fundo, Passo Fundo, Brazil. He is currently at the Federal University of Santa Maria, where he has been a Professor at the Colégio Técnico Industrial de Santa Maria and a Researcher in
[15] F. T. Wakabayashi, C. A. Canesin, "Metodologia De Projeto Para O Filtro Ressonante LCC de Reatores Eletrônicos com Controle de Luminosidade para Lâmpadas Fluorescentes", Eletrônica de Potência SOBRAEP, vol. 9, n 1, pp. 71-79, June 2004.

[16] H. V. Marques, A. R. Seidel, M. S. Perdigão, J. M. Alonso, E. S. Saraiva, "Resonant Circuit Design Procedure For Multi-watt T5 Electronic Ballasts", Eletrônica de Potência - SOBRAEP, vol. 18, $\mathrm{n}^{\circ}$ 1, pp. 831-842, February 2013.

[17] H. Pinheiro, P. K. Jain, G. Joós, "Self-Sustained Oscillating Resonant Converters Operating Above the Resonant Frequency", IEEE Transactions on Power Electronics, vol. 14, no. 5, pp. 803-815, September 1999. M. Cervi, A. R. Seidel, F. E. Bisogno, R. N. do Prado, "Fluorescent Lamp Model Based on the Equivalent Resistance Variation", Proc. In IEEE IAS, vol. 2, pp. 1249-1253, 2001.

the Electronic Ballast Research Group since 1997 and the Electrical and Computational Systems Research and Development Group since 2010. His research interests include resonant converters, dimming systems, simulation, discharge lamps, and lighting systems. Dr. Seidel is a member of the SOBRAEP - Brazilian Power Electronics Society, and IEEE.

Marina Mendes Sargento Domingues Perdigão was born in Coimbra, Portugal, in 1978. She received the M.Sc. degree in electrical engineering from the University of Coimbra, Coimbra, in 2004. She has been working toward the Ph.D. degree from the University of Coimbra in cooperation with the University of Oviedo, Oviedo, Spain, since 2006. Since 2002, she has been an Assistant Professor in the Department of Electrical Engineering, Superior Institute of Engineering of Coimbra, Coimbra. Since 2001, she has also been a Researcher at the Instituto de Telecomunicações. Coimbra. Her research interests include high-frequency electronic ballasts, discharge lamp modeling, high-frequency switching converters, resonant converters, power electronics for renewable energies, and computer simulation applications. Dra. Perdigão received the Best Paper Award of the 2009 IEEE International Symposium on Industrial Electronics. She also collaborates as an IEEE Transactions Paper Reviewer.

José Marcos Alonso Álvarez received the M.Sc. Degree and $\mathrm{Ph} . \mathrm{D}$. both in electrical engineering from the University of Oviedo, Spain, in 1990 and 1994 respectively. Since 2007, he has been appointed as full Professor at the Electrical Engineering Department of the University of Oviedo.

Prof. Alonso is co-author of more than three hundred journal and conference publications. His research interests include electronic ballasts, LED power supplies, power factor correction and switching converters in general. He was supervisor of seven Ph.D. Thesis and he is the holder of seven Spanish patents.

Prof. Alonso has been awarded with the Early Career Award of the IEEE Industrial Electronics Society in 2006. He also holds three IEEE paper awards. Since October 2002 he serves as an Associate Editor of the IEEE Transactions on Power Electronics. He has been Co-Guest Editor of two special issues in lighting applications published in the IEEE Transactions on Power Electronics (2007) and IEEE Transactions on Industrial Electronics (2012) and has coorganized several conference special sessions. He is also member of the European Power Electronics Association and he belongs to the International Steering Committee of the European Conference on Power Electronics and Applications (EPE). 